\title{
Process Optimization for Biodiesel Production from Corn Oil and Its Oxidative Stability
}

\author{
N. El Boulifi, A. Bouaid, M. Martinez, and J. Aracil \\ Department of Chemical Engineering, Faculty of Chemistry, Complutense University, 28040 Madrid, Spain \\ Correspondence should be addressed to J. Aracil, jam1@quim.ucm.es
}

Received 1 December 2009; Revised 3 March 2010; Accepted 4 March 2010

Academic Editor: Michael K. Danquah

Copyright () 2010 N. El Boulifi et al. This is an open access article distributed under the Creative Commons Attribution License, which permits unrestricted use, distribution, and reproduction in any medium, provided the original work is properly cited.

Response surface methodology (RSM) based on central composite design (CCD) was used to optimize biodiesel production process from corn oil. The process variables, temperature and catalyst concentration were found to have significant influence on biodiesel yield. The optimum combination derived via RSM for high corn oil methyl ester yield (99.48\%) was found to be $1.18 \%$ wt catalyst concentration at a reaction temperature of $55.6^{\circ} \mathrm{C}$. To determine how long biodiesel can safely be stored, it is desirable to have a measurement for the stability of the biodiesel against such oxidation. Storage time and oxygen availability have been considered as possible factors influencing oxidative instability. Biodiesel from corn oil was stored for a period of 30 months, and the physico-chemical parameters of samples were measured at regular interval of time. Results show that the acid value (AV), peroxide value (PV), and viscosity $(\nu)$ increased while the iodine value (IV) decreased. These parameters changed very significantly when the sample was stored under normal oxygen atmosphere. However, the $v, A V$, and IV of the biodiesel sample which was stored under argon atmosphere were within the limit by the European specifications (EN 14214).

\section{Introduction}

In the last few years, the world's energy demand is increasing due to the needs from the global economic development and population growth. However, the most important part of this energy currently used is the fossil energy sources. The problem is fossil fuels are nonrenewable. They are limited in supply and will one day be depleted. There is an increased interest in alternative renewable fuels. As biodiesel is an environmentally friendly fuel, it is the best candidate to replace fossil-diesel, which has lower emissions than that of fossil-diesel, it is biodegradable, nontoxic, and essentially free of sulphur and aromatics [1]. However, only nitrogen oxides increase using biodiesel as fuels $[2,3]$.

Renewable feedstocks such as vegetable oils and animal fats have been used as raw materials for biodiesel production [4]. The general way to produce biodiesel fuels is transesterification of fat or oil triacylglycerols with short-chain alcohol such as methanol or ethanol in presence of alkaline or acid catalysts [5-7].

Vegetable oils are promising feedstocks for biodiesel production since they are renewable origin and can be produced on a large scale. More than 95\% of biodiesel production feedstocks come from edible oils since they are varying considerably with location according to climate and availability. In the United States, soybean oil is the most common biodiesel feedstock, whereas in Europe and in tropical countries, rapeseed oil and palm oil are the most common source for biodiesel, respectively, [8]. However, some of these oil sources are commodities whose prices are strongly influencing biodiesel cost, generally in the proportion of $70-80 \%$ [9]. In order to reduce the biodiesel cost, many researchers are interested in waste edible oils [10] and nonedible oils like karanja, mahua and jatropha $[7,11,12]$.

Another alternative comes into play when looking to other industries. That is the case of ethanol, whose primary feedstock is corn. Plants ethanol from corn gives the integrated biorefineries a hydrocarbon-based source of renewable carbon for the production of fuels and chemicals. Ethanol is formed when starch is subjected to hydrolysis, followed by glucose fermentation. During this process, also some by-products including corn gluten meal, gluten feed and corn oil are formed. Therefore, corn oil can be extracted 
as a by-product by using new technology that will make ethanol production more efficient. This corn oil can be converted into a biofuel, such as biodiesel [13].

Biodiesel is being commercialized as a substitute or blending stock of fossil-diesel. However, biodiesel is less resistant to oxidation than typical fossil fuel and therefore doping of biodiesel in fossil-diesel will affect the stability of fuel significantly [14]. Thus, as the demand and the production of biodiesel grows fast, the development of methods to ensure the quality of the biodiesel industry and standardization becomes an urgent topic for market introduction of biodiesel.

As corn biodiesel chemically is a mixture of long-chain fatty acid methyl esters (FAMEs), it is more susceptible to autoxidation and thus has a higher level of chemical reactivity than fossil-diesel. This oxidation instability is dependant on the number and location of methyleneinterrupted double bounds in the FAMEs. Thus carbons that are simultaneously allylic to two olefinic groups will be extremely susceptible to the initiation of peroxidation. An early study [15] measured the relative rate of oxidation for the methyl esters of oleic $(18: 1)$, linoleic $(18: 2)$ and linolenic $(18: 3)$ acids to be $1: 12: 25$.

A number of reports have appeared on the storage and oxidative stability of biodiesel synthesized from different vegetable and frying oils (including sunflower, soybean and rapeseed oil) [16-18]. However, there is no available information about storage stability of biodiesel from corn oil. These stability studies were carried out under different storage condition, such as elevated temperature and exposure to light, air, water, and other contaminants. In other studies biodiesel was subjected to accelerated methods of oxidation, including EN 14112 (Rancimat method) and pressurized differential scanning calorimetry $[19,20]$. The oxidation stability does not only depend on the raw material on the production process, but also on how the oil pressed and refined [21].

In a previous work [16], long-term storage tests on biodiesel from different sources have been conducted under different storage condition. Some chemicals properties have been severely affected by oxidation of the FAMEs, when the biodiesel was exposed to air and daylight. In order to understand whether normal oxygen atmosphere availability can adversely affect these properties, the study of the change in chemical and physical proprieties of biodiesel in absence of oxygen (under argon atmosphere) becomes necessary.

In this paper, the storage stability of biodiesel made from corn oil was investigated over a storage time of 30 months under argon atmosphere conditions, whose properties were compared to a corn biodiesel sample which stored under normal oxygen atmosphere. The focus of the study was on the influence of storage time on the biodiesel properties, such as PV, AV, IV and $\nu$. This work also discusses the results of experiments carried out to evaluate the different variables affecting the alkaline methanolysis of corn oil. The optimum value for the variables affecting the process will be determined by application of factorial design and response surface methodology.
Factorial design of experiments gives more information per experiment than unplanned approaches; it allows to see interactions among experimental variables within the range studied, leading to better knowledge of the process and therefore reducing research time and costs [22].

\section{Experimental Section}

2.1. Equipment. Reactions were carried out in a batch stirred reactor of $500 \mathrm{~cm}^{3}$ volume, equipped with a reflux condenser and a mechanical stirrer. The impeller speed was set at $600 \mathrm{rpm}$ to avoid external mass transfer limitation [6].

2.2. Materials. Corn oil was supplied by Koipe Spain. The quality control of the corn oil used in this study is presented in Table 1. The characteristics were determined according to AOCS official method. Methanol of $99.8 \%$ purity was supplied by Panreac (Spain). The catalyst used was potassium hydroxide purchased from Merck (Barcelona, Spain).

2.3. Production of Corn Oil FAMEs. The corn oil FAMEs were produced via a transesterification process in which a strong alkali catalyst was used. This latter is frequently used in the transesterification reaction, primarily due to its significant advantages in terms of the smaller quantity of catalyst used and the shorter reaction time required [6].

Corn oil was used as the raw oil to be transesterified with methanol in a reacting tank. The temperature values are below the boiling point of methanol $\left(63^{\circ} \mathrm{C}\right)$, to prevent the methanol in the reactant mixture from evaporating. The molar ratio of the methanol and corn oil was set at $6: 1$. The potassium hydroxide was stirred with methanol for 10 minutes using an electric-magnetic stirrer to form potassium methoxide, which was then poured into the reacting tank and mixed with the corn oil. The total reaction time was 60 minutes. Almost total conversion to corn oil FAMEs was achieved quickly after a few minutes from the start of the reaction, depending on the reaction conditions.

2.3.1. Fatty Acid Methyl Esters (FAMEs) Purification. At the end of a run the reaction mixture was allowed to cool down. The upper phase consisted of FAME, and the lower phase was glycerol.

Once the glycerol and FAME phases have been separated, the last one was purified by gentle washing with distilled water to remove residual catalyst, glycerol, and soaps. The $\mathrm{pH}$ of washing water was initially very high 10.22 due to the dissolved $\mathrm{KOH}$. After 3 successive rinses with water, the washing water became clear and its $\mathrm{pH}$ was 7.9. The washing process was continued (twice more) until a $\mathrm{pH}$ of about 7 was achieved. Finally, the methyl ester phase was distilled to remove the residual water.

The final water content of the corn oil FAME was less than $0.01 \%$. Water in the sample can promote microbial growth, lead to tank corrosion, participate in the formation of emulsions, as well as cause hydrolysis or hydrolytic oxidation [23]. 
TABLE 1: Composition analysis results of corn oil.

\begin{tabular}{lccccccccc}
\hline PV & AV & $v$ & IV & \multicolumn{4}{c}{ Main fatty acid composition (\%) } \\
$(\mathrm{meq} / \mathrm{Kg})$ & $(\mathrm{mg} \mathrm{KOH} / \mathrm{g})$ & $\left(\mathrm{cst}\right.$ at $\left.40^{\circ} \mathrm{C}\right)$ & $\left(\mathrm{mg} \mathrm{I}_{2} / \mathrm{g}\right)$ & $\begin{array}{c}\text { Palmitic } \\
(\mathrm{C} 16: 0)\end{array}$ & $\begin{array}{c}\text { Stearic } \\
(\mathrm{C} 18: 0)\end{array}$ & $\begin{array}{c}\text { Oleic } \\
(\mathrm{C} 18: 1)\end{array}$ & $\begin{array}{c}\text { Linoleic } \\
(\mathrm{C} 18: 2)\end{array}$ & $\begin{array}{c}\text { Linolenic } \\
(\mathrm{C} 18: 3)\end{array}$ & other \\
\hline 2.26 & 0.23 & 39.28 & 125.4 & 12 & 2.4 & 27.3 & 55.8 & 1 \\
\hline
\end{tabular}

PV: peroxide value; AV: acid value; $v$ : viscosity; IV: iodine value.

2.4. Analytical Method. Reaction products were monitored by capillary column gas chromatography, using a HewlettPackard 5890 series II equipped with a flame ionization detector (FID). The injection system was split-splitless. The carrier gas was helium at a flow rate of $1 \mathrm{~mL} /$ minutes. The analytical procedures and operating conditions have been described in detail in a previous work [24]. The internal standard technique was used to quantify the amount of the chemical species.

2.5. Preparation the FAME Samples. Two biodiesel samples, three litres each of were stored at ambient temperature for 30 months at two different storage conditions: the samples were stored in closed glass exposed to daylight, one under normal oxygen conditions and the other under atmosphere argon. During storage, samples were taken out periodically and different quality parameters (PV, AV, IV, and $v$ ) were monitored. The analyses were done according to the following procedures: PV (AOCS Cd 8-53), AV (AOCS-Ca $5 \mathrm{a}-40$ ), $v$ (ISO 3104), and IV (AOCS cd 1-25).

\section{Results and Discussion}

3.1. Statistical Analysis. The synthesis of biodiesel was studied using factorial design of experiments. The experimental design applied to this study was a full two-level factorial design $2^{2}$ (two factors each, at two-levels) and extended to response surface methodology (RSM).

The response selected, $Y$, was the yield of methyl ester. The factors chosen were reaction temperature, $X_{T}$, and initial catalyst concentration, $X_{C}$. Initial alcohol/oil molar ratio was fixed at $6: 1$.

Selection of the levels was carried out based on the results obtained in preliminary studies [25]. Temperature levels were selected according to reactants properties, thus the lower value was set at $34.4^{\circ} \mathrm{C}$ and the higher at $55.6^{\circ} \mathrm{C}$. The levels of catalyst concentration were chosen on the basis of preliminary experiments where the amount of catalyst was progressively increased, and the ester yield monitored versus time. The levels chosen were 0.86 and $1.18 \mathrm{wt} . \%$, based on the total mass reaction.

The statistical analysis was thereafter applied. The experimental matrix for the factorial design is shown in Table 2. All the runs were performed at random. Four experiments were carried out at the centre point level, coded as "0", for experimental error estimation.

The use of analysis and factorial design of experiments allowed us to express the amount of ester produced as a polynomial model (if the levels of the factors are equally spaced, then orthogonal polynomials may be used). The
TABLE 2: Experimental matrix and experimental results.

\begin{tabular}{lccccc}
\hline Run & $X_{C}$ & $X_{T}$ & $C(\%)$ & $T\left({ }^{\circ} \mathrm{C}\right)$ & $Y(\%)$ \\
\hline 1 & -1 & -1 & 34.4 & 0.86 & 94.40 \\
2 & +1 & -1 & 55.6 & 0.86 & 98.25 \\
3 & -1 & +1 & 34.4 & 1.18 & 96.50 \\
4 & +1 & +1 & 55.6 & 1.18 & 99.48 \\
5 & 0 & 0 & 45 & 1.02 & 98.25 \\
6 & 0 & 0 & 45 & 1.02 & 97.85 \\
7 & 0 & 0 & 45 & 1.02 & 98.30 \\
8 & 0 & 0 & 45 & 1.02 & 98.40 \\
9 & $-\alpha$ & 0 & 30 & 1.02 & 97.50 \\
10 & $+\alpha$ & 0 & 60 & 1.02 & 98.70 \\
11 & 0 & $-\alpha$ & 45 & 0.80 & 96.9 \\
12 & 0 & $+\alpha$ & 45 & 1.24 & 96.4 \\
\hline
\end{tabular}

Note: $T$ : temperature; $C$ : catalyst concentration; $X$ : coded value; $Y$ : biodiesel yield.

response, yield of ester, may be thus expressed as a function of the significant factors.

3.1.1. Linear Stage. A linear stage was considered in the first step. Table 2 shows the experiments corresponding to the $2^{2}$ factorial design (experiments 1-4) and four experiments in the centre point to evaluate the experimental error (experiments 5-8). A statistical analysis was carried out on these experimental values, and the main effects and interaction effects of the variables were calculated. The analysis of the main effects and its interaction for the chosen response and the test of statistical significance are given in Table 3.

Temperature $\left(X_{T}\right)$, catalyst concentration $\left(X_{C}\right)$, and catalyst concentration-temperature interaction effects $\left(X_{T C}\right)$ were fitted by multiple regression analysis to a linear model. The response function for the significant main effects and interactions is

$$
Y=97.16+1.7 X_{C}+0.83 X_{T}-0.21 X_{T C}, \quad r=0.98 .
$$

The statistical analysis of experimental results revealed that the most significant factor is the catalyst concentration, while it also shows a significant value for curvature for the chosen responses. These data indicate the nonlinearity of the model and thus justifies planning a more complex design to fit the data to a second-order model.

3.1.2. Nonlinear Stage. To better predict the effect of variables, a quadratic model was investigated. Here, the $2^{2}$ 
TABLE 3: $2^{2}$ factorial design: statistical analysis.

\begin{tabular}{ll}
\hline Response: & $Y(\%)$ \\
\hline Number of experiments: & 4 \\
Degree of freedom: & 3 \\
Results of statistical analysis & \\
$\quad Y$ (average) & 97.16 \\
\hline
\end{tabular}

\begin{tabular}{lcl}
\hline & Main effects and interactions & \\
& $X_{T}=1.66, \quad X_{C}=3.41, \quad X_{T C}=-0.43$ & \\
\hline & Statistical Significance of $t$-test & Standard deviation, $S=0.24$ \\
Confidence level: $95 \%$, & Confidence interval: \pm 0.38 \\
Student's $t$ value, $t=3.182$, & Significant effects and Interactions: $X_{T}(+), X_{C}(+), X_{T C}(-)$ & \\
\hline
\end{tabular}
Statistical significance of curvature

$Y_{C}=98.2, Y=97.16$

Curvature: $Y_{C}-Y-=1.04$

$S=0.11, t=3.182$

Confidence curvature interval: \pm 0.54 Curvature: significant

Response equation:

$Y=97.16+1.7 X_{C}+0.83 X_{T}-0.21 X_{T C}$ $r=0.98$

experiment design was expanded to a circumscribed central composite design by the addition of 4 new experiments (run $9-12$ in Table 2), called start points and coded $\pm \alpha$. The value of $\alpha$, which is the distance from the center point to the start point, is $2^{n / 4}$, where $\mathrm{n}$ is the number of factors (for two factors, $\alpha=1.414$ ). The corresponding model is the complete quadratic surface between response and the factors, given by the equation

$$
Y=\beta_{0}+\sum_{i=1}^{2} \beta_{i} X_{i}+\sum_{i=1}^{2} \beta_{i i} X_{i}^{2}+\sum_{i \neq j}^{2} \beta_{i j} X_{i} X_{j},
$$

where $Y$ is the response (methyl ester yield), $X_{i}$ and $X_{j}$ are the uncoded independent variables, and $\beta_{0}, \beta_{i}, \beta_{i i}$, and $\beta_{i j}$ are intercept, linear, quadratic and interaction constant coefficients, respectively.

The coefficients of (2) were determined by multiple regression analysis. This analysis includes all the independent variables and their interactions, regardless of their significance levels. The best-fitting response surfaces found can be written as follows:

$$
\begin{aligned}
Y= & 98.2+1.06 X_{C}+0.32 X_{T}-0.21 X_{T} X_{C}+0.82 X_{T}^{2} \\
& -0.1 X_{C}^{2}, \quad r=0.97 .
\end{aligned}
$$

The statistical model was obtained from coded levels. Equation (3) can be represented as dimensional surfaces and contour plots, as shown in Figure 1. These show the ester yield predicted for the experimental range of temperature and initial catalyst concentration. The influence of these variables on the ester yield will now be discussed. The influence of the main factors and interactions will be derived from (1) and (3).

3.1.3. Influence of Temperature. For both linear and nonlinear models, the temperature influence is statistically

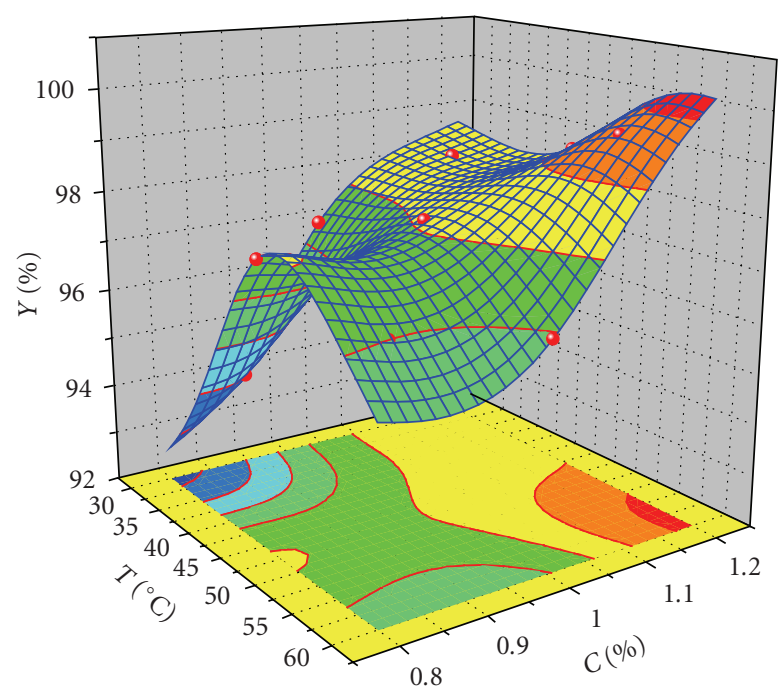

FIGURE 1: Experimental yield versus temperature and catalyst concentration.

significant in the range studied. This effect has a positive influence on the response. As the temperature increases, the solubility of methanol in the oil increases and so does the speed of reaction. As a matter of fact, at low temperatures, methanol is not soluble at all in the oil; when the stirring is started an emulsion appears. The reaction takes place at the interface of the droplets of alcohol in the oil and then as soon as the first FAMEs are formed, the alcohol solubilizes progressively because the esters are mutual solvents for the alcohol and the oil.

3.1.4. Influence of Catalyst Concentration. From the statistical analysis it can be concluded that, within the experimental range, initial catalyst concentration is the most important 


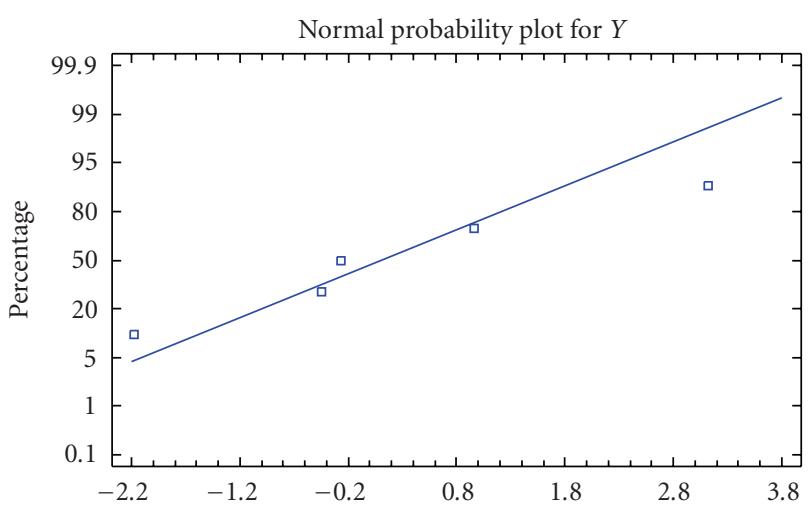

FIGURE 2: Normal probability plot for the methyl esters yield.

factor on the transesterification process. It has a positive influence on the response; that is, ester yield increases with increasing catalyst concentration.

3.1.5. Influence of Interaction. The nonlinear model (Central Composite Design) gives the binary influences of all the factors used in the design. Interaction of significant main effects temperature and catalyst concentration $(T-C)$ is significant and has a negative influence on the process, this effect may be due to the formation of by-products (soaps).

3.1.6. Analysis of Response: Yield of Ester. The ester yield generally increases with increasing catalyst concentration and temperature, but progressively decreases at higher level of temperature and lower level of catalyst concentration. This finding may be explained by the formation of by-products, possibly due to triglycerides saponification processes, a side reaction which is favoured at high temperatures. This side reaction produces potassium soaps and, thus, decreases the ester yield.

The surface plot and contours of ester yield versus temperature and catalyst concentration obtained when individual experimental data are plotted are shown in Figure 1. A comparison among these plots shows that the maximum ester yield is achieved at the higher level for both temperature and catalyst concentration. Figure 2 present a normal probability plot of methyl ester yield which confirmed the significant influence of catalyst and temperature in the range studied. Figure 3 present a plot of the residual distribution, defined as the difference between calculated and observed values, over the observed values for the response studied FAME. The quality of the fit is good because the residual distribution does not follow a trend with respect to the predicted variables. All the residuals are smaller than $1.7 \%$ for FAME yield, which indicate that the model adequately represent the methyl ester yield over the experimental range studied.

Figure 4 presents the plot of experimental values versus predicted ones for biodiesel from Corn oil. From this figure, it can be observed that there are no tendencies in the linear regression fit, so the model explains the experimental range studied adequately.

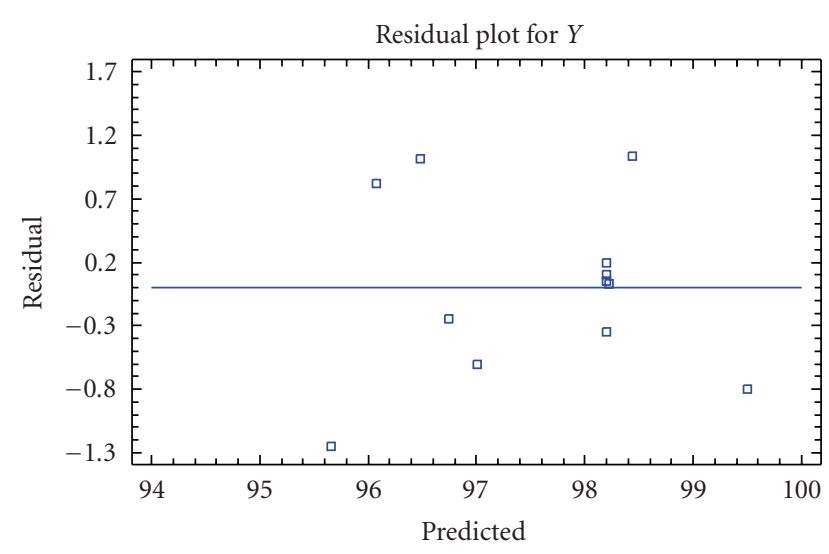

FIGURE 3: Residual plot of methyl esters yield for the second-order model.

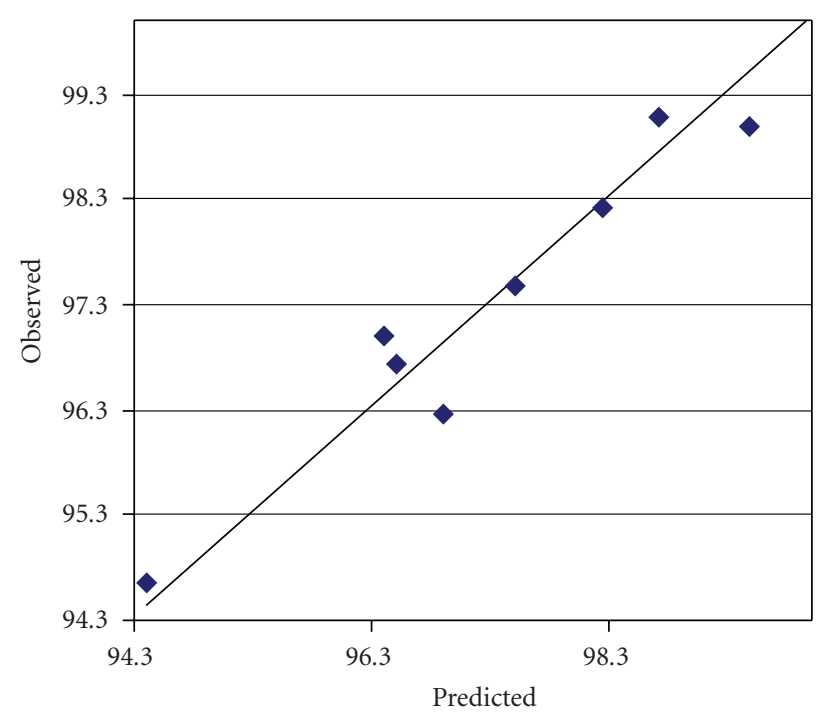

FIgURE 4: Experimental versus predicted values.

3.2. Long Storage Stability of Biodiesel. The oxidation reactions affect the fuel quality of biodiesel, primarily during extended storage. The oxidation stability study was conducted for a period of 30 months. At regular intervals, samples were taken to measure the following physicochemical quality parameters: PV, AV, IV, and $v$.

Some of the most important qualities of biodiesel are shown before and after storage in Table 4. These parameters were compared with some of the biodiesel standards (European Union Standards, EN 14214).

3.2.1. Peroxide Value $(P V)$. Although $\mathrm{PV}$ is less suitable for monitoring oxidation [26], and is not specified in the biodiesel fuel standards, this parameter influences cetane number $(\mathrm{CN})$, a parameter that is specified in the fuel standard. An increase in PV involves an increase in $\mathrm{CN}$, and therefore may reduce ignition delay time [27]. The variation of PV of corn oil FAME in two different storage conditions is shown in Figure 5. Sample stored under argon atmosphere showed an increase in PV from 3 to $19.6 \mathrm{meq} / \mathrm{kg}$ 
TABLE 4: Quality control of corn oil biodiesel fuels used in this study before and after storage time of 30 months compared to EN 14214

\begin{tabular}{|c|c|c|c|c|c|}
\hline \multirow{2}{*}{ Properties } & \multirow{2}{*}{ Unit } & \multirow{2}{*}{$\begin{array}{l}\text { Corn biodiesel } \\
\text { before storage }\end{array}$} & \multicolumn{2}{|c|}{ Corn biodiesel after storage } & \multirow{2}{*}{$\begin{array}{l}\text { Specification EN } \\
14214\end{array}$} \\
\hline & & & $\begin{array}{l}\text { Under argon } \\
\text { atmosphere }\end{array}$ & $\begin{array}{l}\text { Under normal } \\
\text { oxygen atmosphere }\end{array}$ & \\
\hline Viscosity at $40^{\circ} \mathrm{C}$ & $\mathrm{mm}^{2} / \mathrm{s}$ & 4.14 & 4.72 & 5.82 & $3.5-5.0$ \\
\hline Density at $15^{\circ} \mathrm{C}$ & $\mathrm{g} / \mathrm{cm}^{3}$ & 0.865 & 0.871 & 0.895 & $0.86-0.90$ \\
\hline Water content & $\mathrm{wt} \%$ & 0.15 & 0.21 & 0.29 & $<0.5$ \\
\hline Biodiesel yield & wt $\%$ & 99.48 & 98.7 & 96.23 & $>96.5$ \\
\hline Monoglyceride content & $\mathrm{wt} \%$ & 0.40 & 0.27 & 0.3 & $<0.80$ \\
\hline Diglyceride content & wt $\%$ & 0.11 & 0.1 & 0.1 & $<0.20$ \\
\hline Triglyceride content & wt $\%$ & 0.0 & 0.0 & 0.0 & $<0.20$ \\
\hline Free glycerol & $\mathrm{wt} \%$ & 0.01 & 0.01 & 0.01 & $<0.02$ \\
\hline Acid value & $\mathrm{mg} \mathrm{KOH/g}$ & 0.047 & 0.21 & 0.7 & $<0.5$ \\
\hline Iodine value & $\mathrm{mg} \mathrm{I}_{2} / \mathrm{g}$ & 126.6 & 98.4 & 80 & $<120$ \\
\hline Peroxide value & $\mathrm{meq} / \mathrm{Kg}$ & 3.0 & 14 & 31.8 & - \\
\hline Cloud point & ${ }^{\circ} \mathrm{C}$ & -5 & -4 & -3 & - \\
\hline Pour point & ${ }^{\circ} \mathrm{C}$ & -6 & -6 & -5 & - \\
\hline Cold filter plugging point & ${ }^{\circ} \mathrm{C}$ & -8 & -8 & -9 & $<-7$ \\
\hline
\end{tabular}

and then a decrease to $14 \mathrm{meq} / \mathrm{kg}$. It can be see that the faster increase rate happens during the first 6 months. The same results were obtained by another author [28]. The reasons why such behaviours exist are not clearly resolved in prior work. However, the increasing of PV during the first 6 months may be due to the presence of the dissolved oxygen remaining in the biodiesel sample that allows the formation of compounds like hydroperoxides. Furthermore, sample stored under normal oxygen atmosphere conditions showed a continuing increase in PV over time. If oxygen is not available in sufficient abundance, the formation of $\mathrm{ROOH}$ can slow or even stop while $\mathrm{ROOH}$ decomposition continues. This will tend to cause a peak in the $\mathrm{ROOH}$ concentration followed by a decrease.

3.2.2. Acid Value $(A V)$. Once the peroxides have formed, they decompose and interreact to form numerous secondary oxidation products including aldehydes, which further oxidized into acids. Acids can also be formed when traces of water cause hydrolysis of the esters into alcohol and acids. Acid value measured in $\mathrm{mg} \mathrm{KOH} / \mathrm{g}$ is one of the significant indicators of oxidative degradation in lipids. The change in AV during storage for the two corn oil FAME samples is shown in Figure 6. It can be seen that the AV increase continuously in sample stored under normal oxygen atmosphere from 0.047 to $0.7 \mathrm{mg} \mathrm{KOH} / \mathrm{g}$. In opposition to it, in the sample stored under argon atmosphere, the $\mathrm{AV}$ increased fast during the first 4 months, and then remained almost constant. This behaviour may be due to the presence of the dissolved oxygen remaining in the biodiesel sample that allows the formation of shorter chain fatty acids [18]. In this case, the specification limit of $0.5 \mathrm{mg}$ $\mathrm{KOH} / \mathrm{g}$ was not exceeded with the corn oil FAME sample stored under argon atmosphere after a storage time of 30 months.

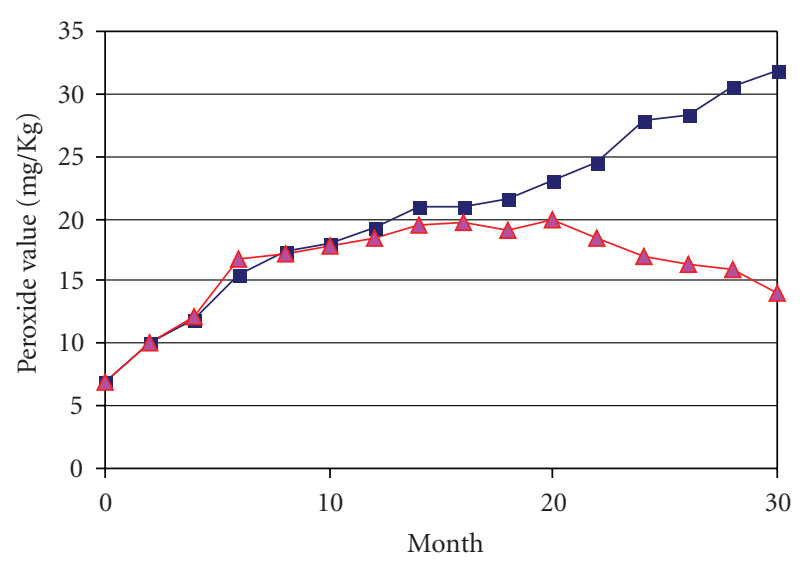

FIGURE 5: Variation in the peroxide value of corn oil biodiesel stored $\square$ under normal oxygen atmosphere and $\boldsymbol{\Delta}$ under argon atmosphere.

3.2.3. Viscosity $(\nu)$. Due to the hydroperoxides decomposition, the oxidative linking of fatty acid methyl ester chains can occur, giving as a result higher molecular weights species. During storage one of the obvious results of polymer formation is an increase in biodiesel viscosity [29]. The formation of higher molecular weight species, with higher viscosity, is a reason why the viscosity specification in biodiesel standards can be used to assess the fuel quality status of stored biodiesel. Figure 7 shows the increase in the kinematic viscosity of the two corn oil FAME samples versus storage time. Corn oil FAME sample which was stored under argon atmosphere, was found to have lower viscosity compared to the sample which was stored under normal oxygen atmosphere. A similar result had been observed previously by other researchers [30]; they noted that the oxidation processes led to the formation of free fatty acids, 


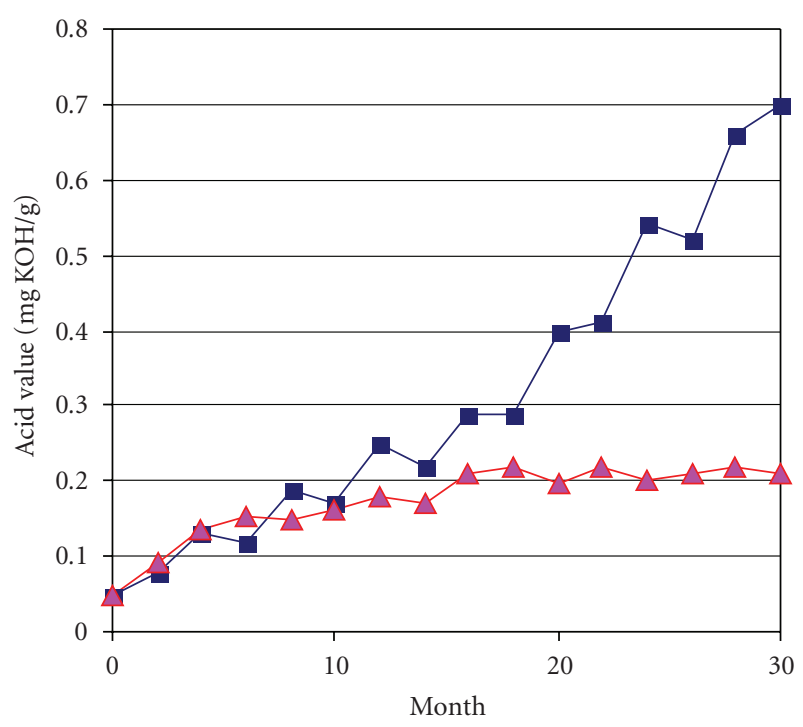

FIGURE 6: Variation in the acid value of corn oil biodiesel stored under normal oxygen atmosphere and $\boldsymbol{\Delta}$ under argon atmosphere.

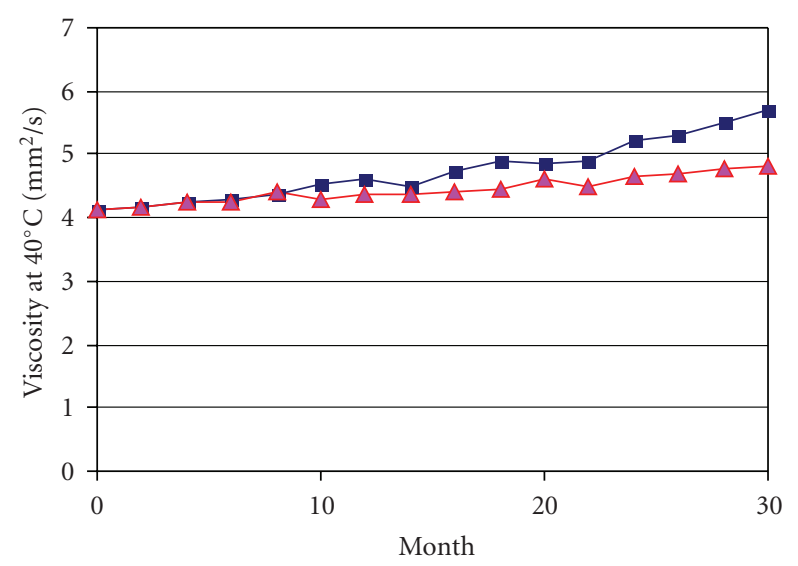

FIGURE 7: Variation in the iodine value of corn oil biodiesel stored under normal oxygen atmosphere and $\boldsymbol{\Delta}$ under argon atmosphere.

double bond isomerization (usually cis to trans), saturation and products of higher molecular weight, and viscosity increases with increasing oxidation. Under conditions where oxygen is available, fatty acid moieties are joined by both $\mathrm{C}-\mathrm{O}-\mathrm{C}$ linkages and $\mathrm{C}-\mathrm{C}$ linkages [31]. When $\mathrm{ROOH}$ decomposition occurs under an inert atmosphere, only $\mathrm{C}-\mathrm{C}$ linkages in resulting polymers are observed [31].

3.2.4. Iodine Value (IV). One of the oldest and most common methods of determining the level of unsaturation in a fatty oil or ester is the iodine value [32], it purportedly addresses the use of oxidative stability and it is included in the European biodiesel standard. Oxidation, which consists of a complex series of chemical reactions, is characterized by a decrease in the total unsaturated content of biodiesel due to elimination of hydrogen adjacent to a double bond and the formation of free radicals [33]. Our experiment shows that the IV of the two corn oil FAME samples fell along the

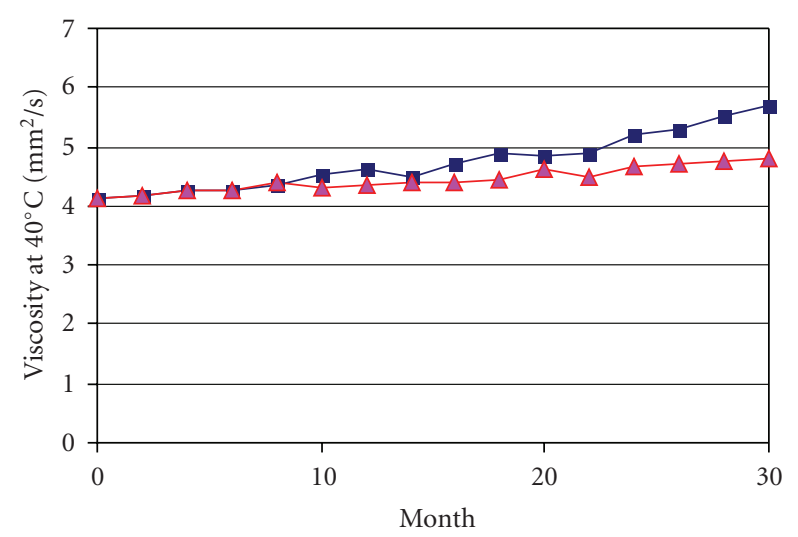

FIgURE 8: Variation in the kinematic viscosity of corn oil biodiesel stored $\square$ under normal oxygen atmosphere and $\boldsymbol{\Delta}$ under argon atmosphere.

storage time (Figure 8). The sample which was stored under normal oxygen atmosphere appeared to have the highest rate of reduction in IV, implying that the largest conversion of polyunsaturated fatty acids to hydroperoxides took place. In contrast to this result, the sample which was stored under argon atmosphere was observed to have low rate of decrease in IV. Corn oil FAME samples (IV $=126.6$ ) with a relatively high IV compared to other biodiesel samples [4]; this sample contains low levels of saturated FAME and high levels of mono- and polyunsaturated FAME which make it much susceptible to oxidation.

For biodiesel samples, the peroxide value, acid values, and viscosity tended to increase, and iodine value to decrease over time. The sample stored under argon atmosphere never exceeded the specification limit of the studied parameters along the 30 months of storage. Biodiesel from corn oil stored under argon atmosphere did not demonstrate rapid increase in peroxide value, acid value and viscosity, compared to the one stored under normal oxygen atmosphere.

When storage is done in argon atmosphere condition, at ambient temperature without oxygen availability, PV, AV, and $v$ increases slowly; while PV peaks and then decreases, $\mathrm{AV}$ and $v$ continue to increase, but at a lower rate. Besides IV decreases during the storage.

Biodiesel kept in an argon atmosphere could increase its stability and also show positive effects retarding oxidative degradation of the biodiesel produced from corn oil.

\section{Conclusions}

In this work, a fully central composite design has been applied to optimize the synthesis process of FAME from corn oil using potassium hydroxide as catalyst. The study of the factors (temperature and catalyst concentration) affecting the response shows that, within, the experimental range considered, the most important factor is the initial catalyst concentration. For the yield of ester, this factor has a positive influence. The temperature has a positive influence in both responses. The $T-C$ interaction is small and negative, due to the formation of by-products (soaps). According 
to this study, and from an economical point of view, the maximum yield of ester $(98.75 \%)$ can be obtained, working with an initial catalyst concentration $(1.1 \%)$ and operation temperature $\left(55^{\circ} \mathrm{C}\right)$. These models are useful to determine the optimum operating conditions for the industrial process using a minimal number of experiments with the consequent economical benefit.

Biodiesel synthesised, which consists of long-chain FAME, generally suffers from lower oxidation stability. Results from this study suggest that for a remarkably stable biodiesel and in order to avoid oxidation, special precautions must be taken during long storage, such as storage under argon atmosphere. Nevertheless this action delays oxidation but it doesnot prevent it. The results of this work have allowed develop a methodology to overcome the obvious problems of long storage stability of biodiesel. Long-term storage study gives us a better understanding of the effect of the normal oxygen atmosphere on the stability of biodiesel. The use of corn oil as an alternative raw material and renewable feedstock to produce biodiesel which fulfills the specification of EU standards for biodiesel (EN 14214) is of great interest to build an integrated and self-sustained biorefinery.

\section{Acknowledgment}

Financial support from the (CICYT), Spanish Project CTQ 2006-10467/PPQ is gratefully acknowledged.

\section{References}

[1] F. Staat and E. Vallet, "Vegetable oil methyl ester as a diesel substitute," Chemistry \& Industry, vol. 21, pp. 856-863, 1994.

[2] M. P. Dorado, E. Ballesteros, J. M. Arnal, J. Gomez, and F. J. L. Gimenez, "Testing waste olive oil methyl ester as a fuel in a diesel engine," Energy \& Fuels, vol. 17, no. 6, pp. 1560-1565, 2003.

[3] N. Usta, "An experimental study on performance and exhaust emissions of a diesel engine fuelled with tobacco seed oil methyl ester," Energy Conversion and Management, vol. 46, no. 15-16, pp. 2373-2386, 2005.

[4] S. P. Singh and D. Singh, "Biodiesel production through the use of different sources and characterization of oils and their esters as the substitute of diesel: a review," Renewable and Sustainable Energy Reviews, vol. 14, no. 1, pp. 200-216, 2010.

[5] J. M. Marchetti, V. U. Miguel, and A. F. Errazu, "Possible methods for biodiesel production," Renewable and Sustainable Energy Reviews, vol. 11, pp. 1300-1311, 2007.

[6] G. Vicente, M. Martínez, and J. Aracil, "Integrated biodiesel production: a comparison of different homogenous catalysts systems," Bioresource Technology, vol. 92, pp. 297-305, 2004.

[7] Y. C. Sharma and B. Singh, "Development of biodiesel from karanja, a tree found in rural India," Fuel, vol. 87, no. 8-9, pp. 1740-1742, 2008.

[8] G. Knothe, "Current perspectives on biodiesel," Information, vol. 13, no. 12, pp. 900-903, 2002.

[9] H. Shi and Z. Bao, "Direct preparation of biodiesel from rapeseed oil leached by two-phase solvent extraction," Bioresource Technology, vol. 99, no. 18, pp. 9025-9028, 2008.
[10] F. Ferella, G. Mazziotti, I. De Michelis, V. Stanisci, and F. Vegliò, "Optimization of the transesterification reaction in biodiesel production," Fuel, vol. 89, pp. 36-42, 2010.

[11] S. V. Ghadge and H. Raheman, "Process optimization for biodiesel production from mahua (Madhuca indica) oil using response surface methodology," Bioresource Technology, vol. 97, no. 3, pp. 379-384, 2006.

[12] A. K. Tiwaria, A. Kumara, and H. Raheman, "Biodiesel production from jatropha oil (Jatropha curcas) with high free fatty acids: an optimized process," Biomass and Bioenergy, vol. 31, no. 8, pp. 569-575, 2007.

[13] GS AgriFuels to Convert Corn Oil into Biodiesel at Ethanol Facilities, GS AgriFuels Corporation, New York, NY, USA, 2006.

[14] R. O. Dunn and G. Knothe, "Oxidative stability of biodiesel in blends with jet fuel by analysis of oil stability index," Journal of the American Oil Chemist's Society, vol. 80, no. 10, pp. 10471048, 2003.

[15] F. D. Gunstone and T. P. Hilditch, "The union of gaseous oxygen with methyl oleate, linoleate, and linolenate," Journal of the Chemical Society, pp. 836-841, 1945.

[16] A. Bouaid, M. Martínez, and J. Aracil, "Long storage stability of biodiesel from vegetable and used frying oils," Fuel, vol. 86, no. 16, pp. 2596-2602, 2007.

[17] A. Bouaid, M. Martínez, and J. Aracil, "Production of biodiesel from bioethanol and Brassica carinata oil: oxidation stability study," Bioresource Technology, vol. 100, no. 7, pp. 2234-2239, 2009.

[18] P. Bondioli, A. Gasparoli, L. D. Bella, and T. Silvia, "Evaluation of biodiesel storage stability using reference methods," European Journal of Lipid Science and Technology, vol. 104, no. 12, pp. 777-784, 2002.

[19] B. R. Moser, "Comparative oxidative stability of fatty acid alkyl esters by accelerated methods," Journal of the American Oil Chemist's Society, vol. 86, no. 7, pp. 699-706, 2009.

[20] R. O. Dunn, "Effect of oxidation under accelerated conditions on fuel properties of methyl soyate (biodiesel)," Journal of the American Oil Chemist's Society, vol. 79, no. 9, pp. 915-920, 2002.

[21] M. H. Chahine and R. F. Macneill, "Effect of stabilization of crude whale oil with tertiary-butylhidroquinone and other antioxidants upon keeping quality of resultant deodorized oil. A feasibility study," Journal of the American Oil Chemist's Society, vol. 51, no. 3, pp. 37-41, 1974.

[22] G. Box and J. Hunter, "Response surface methods," in Statistics for Experiments Part IV: Building Models and Using Them, chapter 5, John Wiley \& Sons, New York, NY, USA, 1978.

[23] G. Knothe, "Analyzing biodiesel: standards and other methods," Journal of the American Oil Chemist's Society, vol. 83, no. 10, pp. 823-833, 2006.

[24] T. Garcia, A. Coteron, M. Martínez, and J. Aracil, "Optimization of the enzymatic synthesis of isopropyl palmitate using a central composite design," Transactions of Chemical Engineers, vol. 73, pp. 140-144, 1995.

[25] G. Vicente, A. Coteron, M. Martínez, and J. Aracil, "Application of the factorial design of experiments and response surface methodology to optimize biodiesel production," Industrial Crops and Products, vol. 8, no. 1, pp. 29-35, 1998.

[26] A. Monyem, M. Canakci, and J. H. Van Gerpen, "Investigation of biodiesel thermal stability under simulated in-use conditions," Applied Engineering in Agriculture, vol. 16, pp. 373-378, 2000. 
[27] G. Knothe, "Structure indices in FA chemistry. How relevant is the iodine value?" Journal of the American Oil Chemist's Society, vol. 79, no. 9, pp. 847-854, 2002.

[28] P. Bondioli, A. Gasparoli, L. D. Bella, S. Tagliabue, and G. Toso, "Biodiesel stability under commercial storage conditions over one year," European Journal of Lipid Science and Technology, vol. 105, no. 12, pp. 735-741, 2003.

[29] H. A. Moser, P. C. Cooney, C. D. Evans, and J. C. Cowan, "The stability of soybean oil: effect of time and temperature on deodorization," Journal of the American Oil Chemist's Society, vol. 43, no. 11, pp. 632-634, 1966.

[30] G. Knothe and K. R. Steidley, "Kinematic viscosity of biodiesel fuel components and related compounds. Influence of compound structure and comparison to petrodiesel fuel components," Fuel, vol. 84, no. 9, pp. 1059-1065, 2005.

[31] M. W. Formo, E. Jungermann, F. Noris, and N. O. V. Sonntag, "Bailey\&s Industrial Oil and Fat Products," in Bailey's Industrial Oil and Fat Products, D. Swern, Ed., vol. 1, pp. 698-711, John Wiley \& Sons, New York, NY, USA, 4th edition, 1979.

[32] G. Knothe and R. O. Dunn, "Dependence of oil stability index of fatty compounds on their structure and concentration and presence of metals," Journal of the American Oil Chemist's Society, vol. 80, no. 10, pp. 1021-1026, 2003.

[33] S. Naz, H. Sheikh, R. Siddiqi, and S. A. Sayeed, "Oxidative stability of olive, corn and soybean oil under different conditions," Food Chemistry, vol. 88, no. 2, pp. 253-259, 2004. 

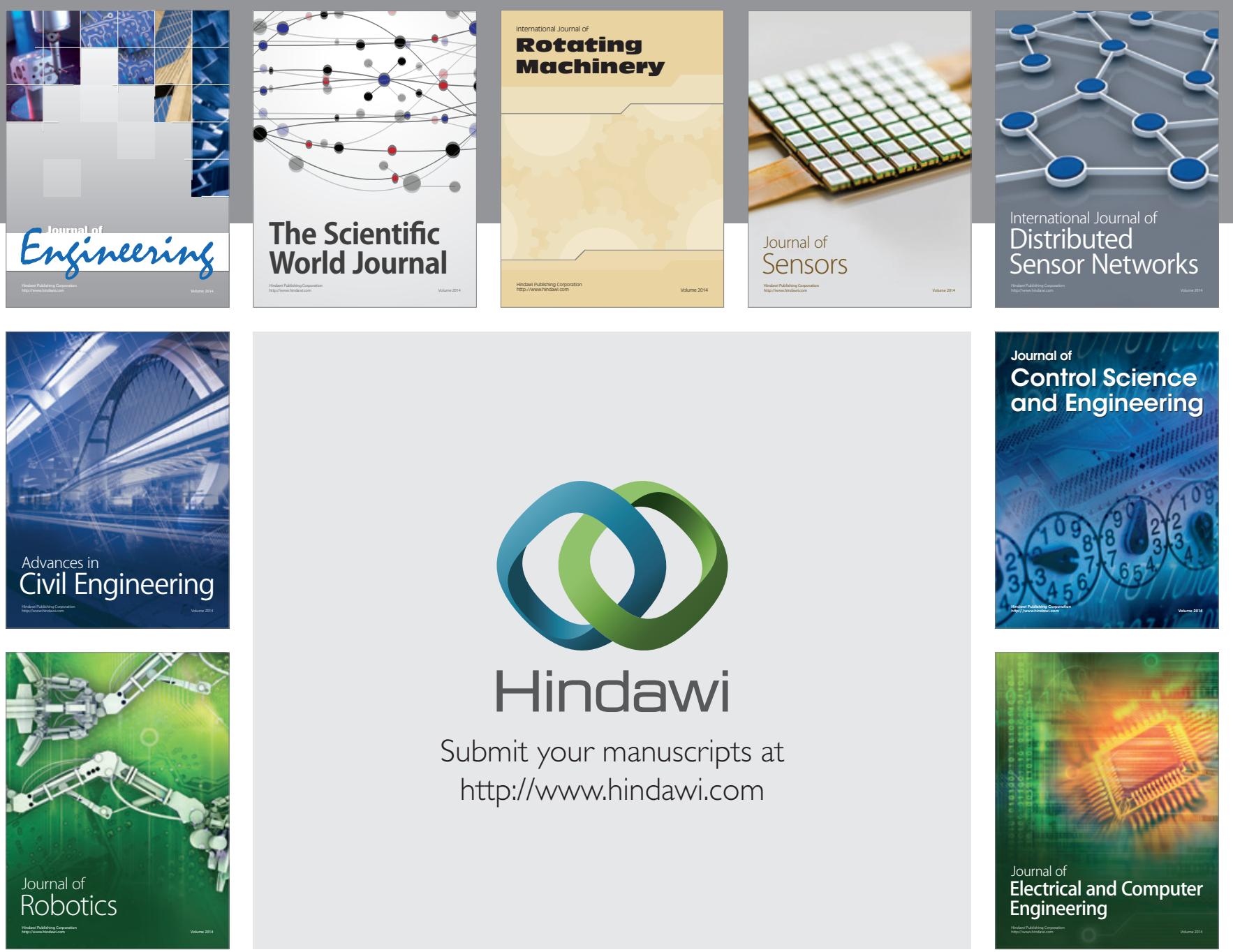

Submit your manuscripts at

http://www.hindawi.com
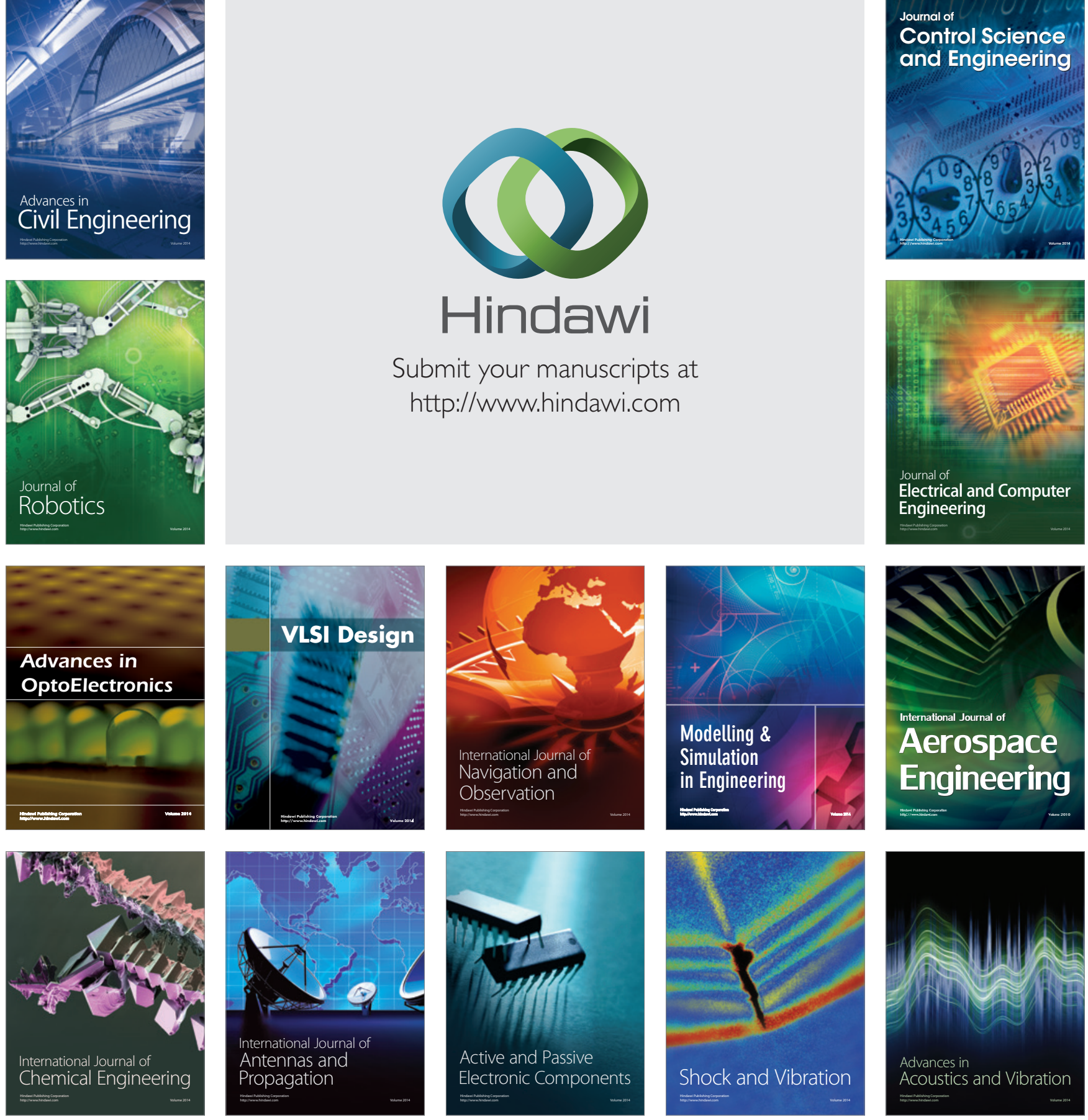